\title{
Determination of the Friction Coefficient in the Flat Strip Drawing Test
}

\author{
Anvar Makhkamov \\ Namangan Institute of Engineering and Technology, Namangan, Uzbekistan \\ Email: anvarmaxkamov@gmail.com
}

How to cite this paper: Makhkamov, A. (2021) Determination of the Friction Coefficient in the Flat Strip Drawing Test. Engineering, 13, 595-604.

https://doi.org/10.4236/eng.2021.1311043

Received: October 11, 2021

Accepted: November 26, 2021

Published: November 29, 2021

Copyright $\odot 2021$ by author(s) and Scientific Research Publishing Inc. This work is licensed under the Creative Commons Attribution International License (CC BY 4.0).

http://creativecommons.org/licenses/by/4.0/

\begin{abstract}
Current work is focused on the influence of friction in deep drawing process. Friction measurements were also conducted using a modified tribotester based on strip sliding between tools. Four different tool surfaces were tested under similar contact conditions regarding contact area, normal pressure, sliding speed, lubricant and surface characteristics to calculate the friction coefficient between the tool surface and a high strength low alloy steel sheet HSLA 380 . The results showed that friction coefficient varies over a wide range with different lubricating conditions and different sliding velocities. For some sliding velocities, the coefficient of friction is stable and low, while for others it is unstable and higher. Results of the experiments reveal that this novel tribotester is a very useful tool to evaluate and compare the friction between steel sheet and tool surfaces in alloyed steel for cold working applications. The outcomes have only small dispersion within the different test series, which indicates a stable process with good repeatability. The test method enables comparison of different surface finishes and treatments, lubricants and coatings in terms of friction and galling under conditions similar to those found in sheet metal forming processes. The four different types of surfaces considered for this study were grinded, polished, nitrided and quenched/tempered. The main difference among the tested tools in this work was the surface roughness, which was found to have a strong influence on friction.
\end{abstract}

\section{Keywords}

Tribology, Friction, Roughness, Sheet Metal Forming, Lubricant, Steel Sheet, Tool Surface, Coefficient of Friction, Normal Force, Sliding Speed, Contact Pressure, Strip Drawing Test

\section{Introduction}

Tribology is the science and technology for friction, lubrication and wear. Tri- 
bology plays a key role in metal forming processes through the relative motion and interaction between the applied sheet material, the lubrication and the tooling. Tribology may determine the quality of metal formed products and may influence the stability and efficiency of the production process.

A modified strip drawing tribotester has been used to generate the movement between the tool and sheet. The uniqueness with this device compared to existing tribotesters used within sheet forming applications is the ability to fully control the applied normal force and drawing velocity during experimentation to simulate true tribological conditions more accurately. This option makes it possible to combine very accurate control of the relative movement between the sheet and the tool with consistent load and pulling force measurement [1] [2].

The test method enables comparison of different surface finishes and treatments, lubricants and coatings in terms of friction and galling under settings similar to sheet metal forming process conditions. Valid frictional data is also very important [3] [4] as an input parameter for simulation models to achieve reliable results.

The basic functioning of the tribotester is illustrated in Figure 1. The linear motion of the tensile testing machine moving table is hydraulically driven. The specification for the linear motion in terms of velocity, distance, force and load is primarily based on estimates from sheet forming processes.

The actuator generating the movement between the tool and sheet, as well as the controllable normal load are the main characteristics of this device and other tribotesters based on parallel strip drawing. This option makes it possible to combine very accurate control of the relative movement between the sheet and the tool with interesting dynamic properties [1] [2].

This work had its focus on the influence of friction under conditions applied to deep drawing processes, by considering different tool materials and finishes,

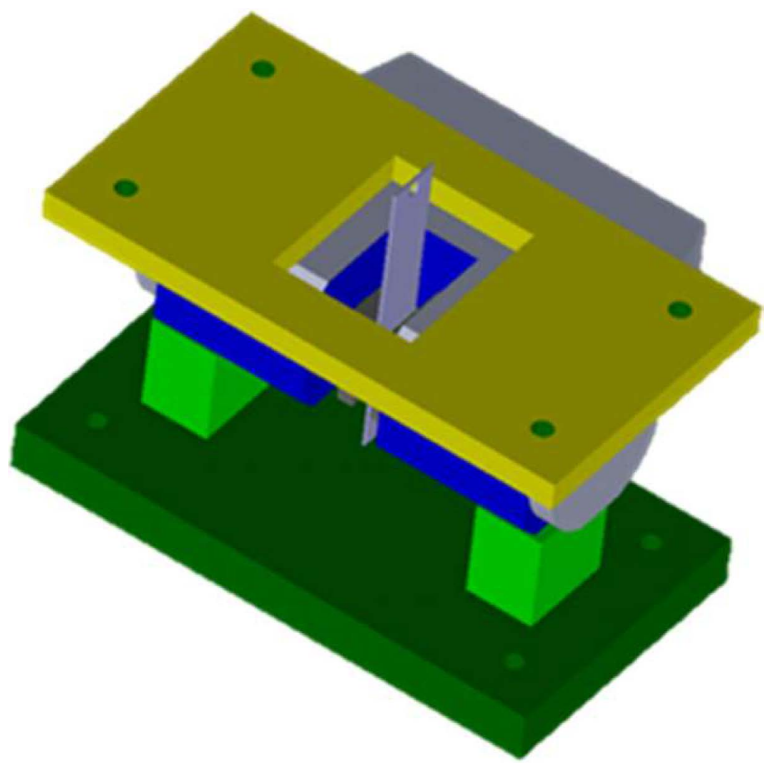

Figure 1. Schematic illustration set of the modified strip drawing tribotester. 
as well as different sheet steels and lubricants. Also, different tribological tests were carried out, which included the pin-on-disc machine and a developed modified strip drawing test, both aimed to simulate behaviour and to investigate the friction between sheet metal and tools during forming.

\section{Experimental Setup and Methods}

Four types of surface textures were produced on tool plates. The surfaces were produced on the steel plates with roughness obtained by grinding. For this type of surface texture, care was taken so that the grinding marks were unidirectional in nature and parallel to sliding direction.

Preliminary experiments were used with similar tool plates having two different types of grinding surfaces: one of them with grinding parallel to the sliding direction and another type with grinding perpendicular to sliding direction. Results with perpendicular grinding have been negative, therefore the experiments with this type of surface finish did not continue in next phase.

Before each experiment, the tool surface and steel sheet samples were thoroughly cleaned with ether alcohol and then the lubricant was applied with a brush. The steel sheet sample was fixed vertically at the grip of the tensile testing machine.

Then steel sheet sample was tested under four different loads at the sliding speeds of 60,150 and $240 \mathrm{~mm} / \mathrm{min}$. Sliding track length for each test was around $150 \mathrm{~mm}$. The average coefficient of friction values were calculated for a sliding track of 100 to $120 \mathrm{~mm}$ and loads were defined for 10.4, 16.25, 32.5 and 48.75 $\mathrm{kN}$. Therefore, the effect of normal load and speed on the coefficient of friction could be studied.

Experiments were conducted under lubricated conditions on each sheet sample using just one combination of load and sliding speed. Before the tests, the lubricant (Renoform EMP 172) was applied on both surfaces of the steel plate. The viscosity of lubricant oil was found to be $68 \mathrm{mPa} \cdot \mathrm{s}$ at $40^{\circ} \mathrm{C}$ [5] [6].

The profiles and surface roughness parameters of the tool materials and steel sheet samples were measured in the direction of the sliding and perpendicular to the sliding direction using two-instruments: Bruker's NPFLEX 3D optical microscope and contact measuring device HOMMEL tester T500.

It was reported that the coefficient of friction depends on sliding direction [7]. For this reason, $2 \mathrm{D}$ roughness parameters, along the sliding direction, were considered in this study. The coefficient of friction values obtained in the experiments were correlated with roughness parameters of the tool surface.

\subsection{The Modified Strip Drawing Tribotester}

The basic functioning of the modified strip drawing tribotester is illustrated in Figure 2. These tests enable faster and more accurate measurement of friction coefficient for metal forming with enriched functionalities.

Strip drawing tests, which consider contact pressure, sliding velocity and sliding length were developed to improve the accuracy of predictions of the coeffi- 
cient of friction of steel sheets. The effects of contact pressure and sliding velocity under lubrication were estimated based on a friction test in which steel sheet was drawn between two tools.

Four different tool surfaces have been selected for strip drawing tests. To study the effect of the roughness peaks on coefficient of friction, grinded and polished surfaces have been tested. Also, to detect the result of different material properties, grinded surfaces have been nitrided and quenched/tempered.

Therefore, some additional tests with steel sheet and tools with different surface finishes have been carried out on the modified strip drawing tribotester, using as much as possible the same experimental conditions. Figure 3 illustrates the basic function and details of the modified tribotester. The tensile testing
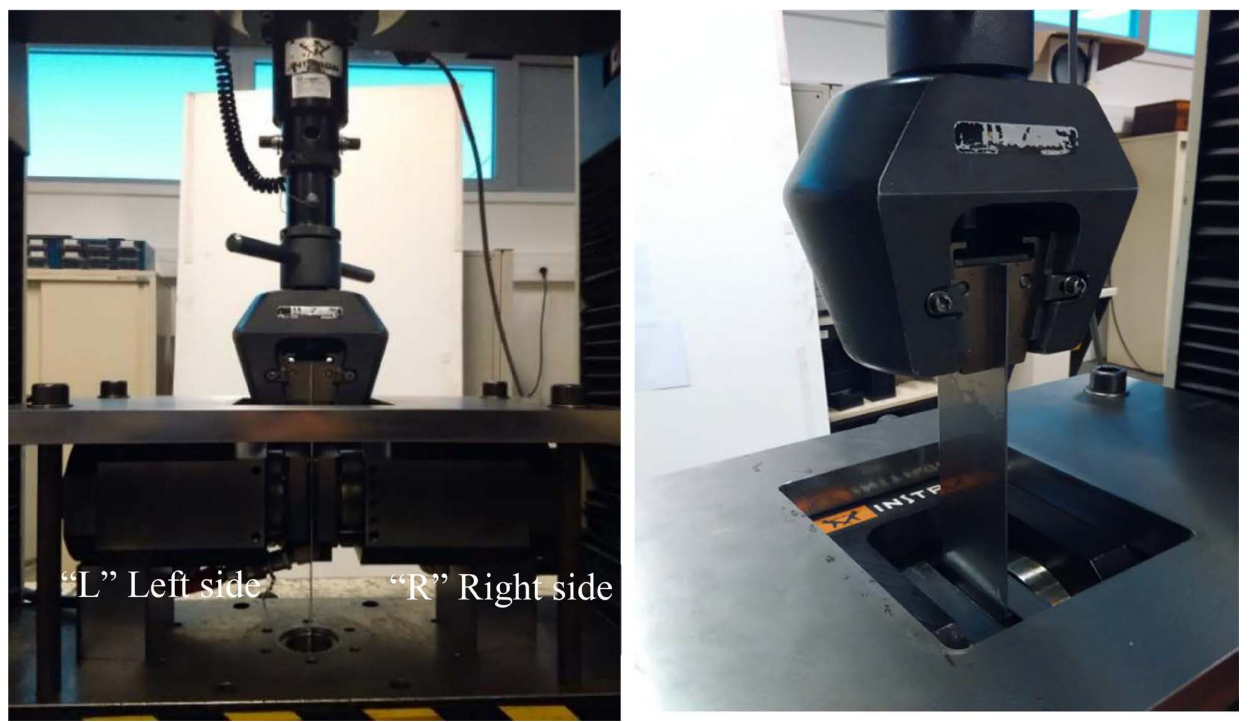

Figure 2. Tool plates set of the modified strip drawing tribotester (L-means Left side of the tool plates, when looking at the front side; $\mathrm{R}$-means Right side of the tool plates).
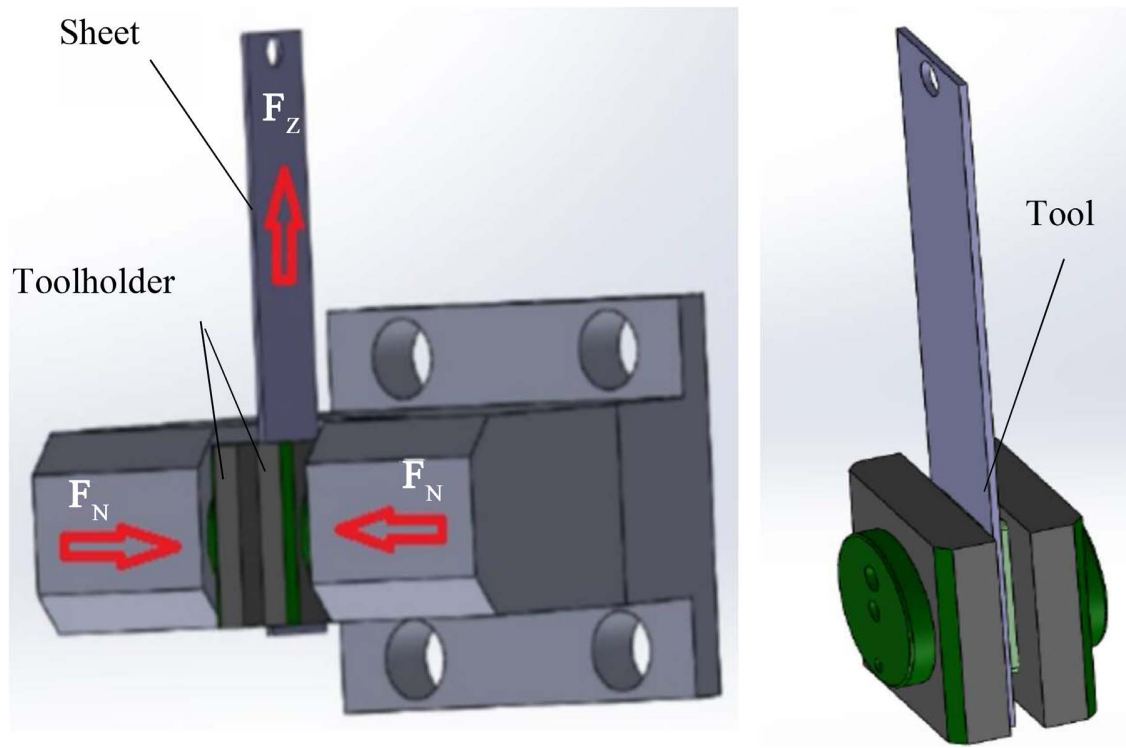

Figure 3. Set of tools and sheet metal layout. 
machine, already mentioned in previous section, was used to provide force and displacement control for the modified strip drawing tribotester.

This tribology-system consists of:

- sheet (material properties, coating/treatment and surface finish);

- tooling (material type, coating/treatment and surface finish);

- lubrication (type of lubricant, liquid, amount and distribution);

- process (pressure, velocity and stroke length).

The current industrial standard is to use a constant (Coulomb) coefficient of friction for calculation proposes. To achieve more realistic simulation results with increased reliability, it is crucial to accurately account for tribology effects in metal forming [1] [2].

\subsection{Tools with Different Surface Finishes}

Four tool couples with different surface topographies are incorporated in this work as considered in Figure 4. The materials are commercial tool steels developed to satisfy different applications within the sheet forming industry. There are no general applicable standards for the materials. Grinded and Polished corresponds to K 340, also Nitrided and Quenched/tempered corresponds to C 265, as seen in Table 1.

The difficulty with cold work applications in general, especially when blanking hard work materials, is to minimize crack initiating defects [8]. This must be done while maintaining wear resistance which demands high hardness and hard particles in the steel matrix.
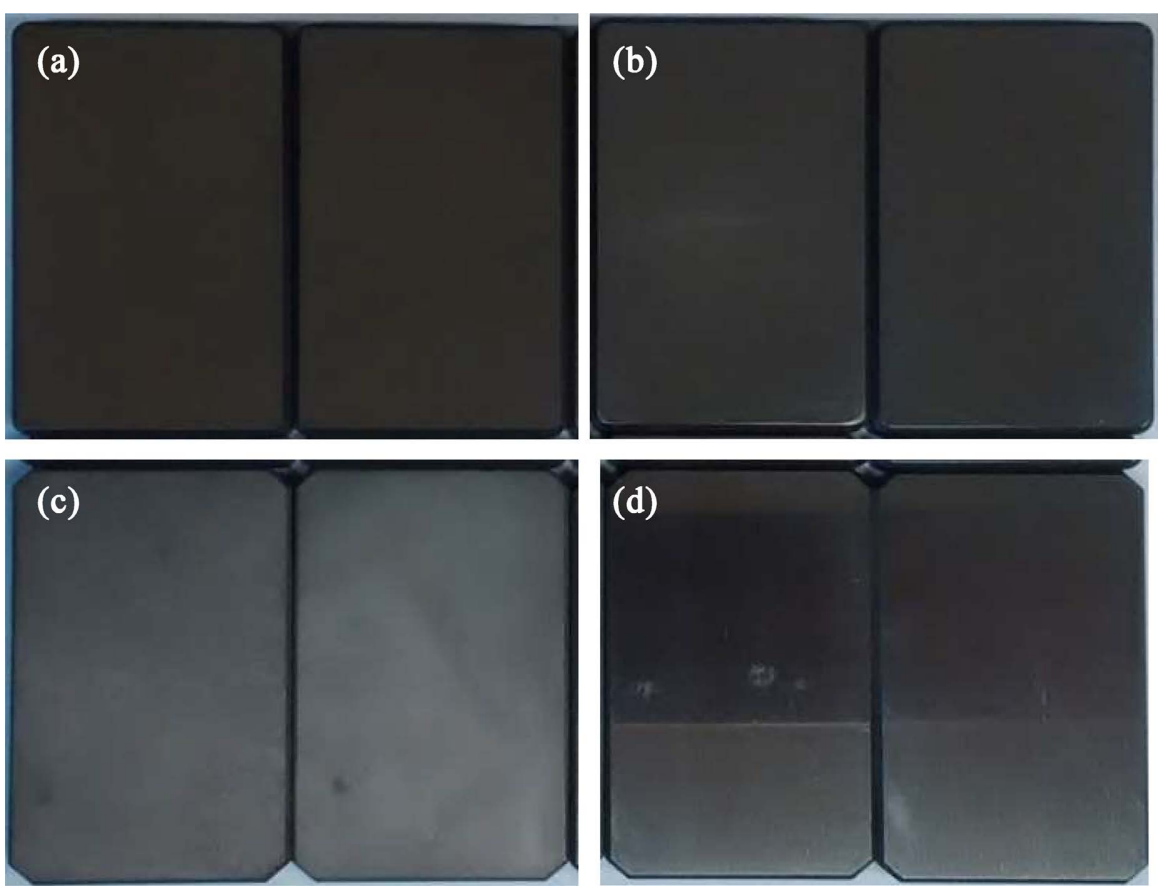

Figure 4. Tool couples with different surface finishes (L-Left plate; R-Right Plate). (a) Grinded "L" and "R"; (b) Polished "L" and "R"; (c) Nitrided "L" and "R"; (d) Quenched/tempered "L" and "R". 
Crack initiating defects such as notches are not necessarily due to carbides. Large slag inclusions, defects in the tool surface or sharp corners in combination with high hardness may also act as sites for crack initiation at fatigue loading. For this reason, the cleanliness of the metallurgical process and the surface finish of the tool or the tool design will strongly influence tool performance [9].

\subsection{Tool Material Properties}

The $12 \%$ chromium tool steels remain the most commonly used materials for cold working tools worldwide. It is a tool steel with very good resistance to abrasive wear, but limited with respect to resistance to fracture. Being the basis of cold work applications, there are numerous advantages in its use, such as heat treatment knowledge and manufacturing parameters. For a tool used in series of medium duration it is a correct choice, where the main failure mechanism is abrasive wear, with low risk of fragmentation or cracking.

The tool materials used in all experiments under this work are K 340 and C 265 steels [8] [9]. The materials are commonly used in cold working tools, such as blanking and stamping tools in the sheet metal forming industry, due to its high resistance to wear and chipping. The chemical composition of the tool materials can be seen in Table 1 .

Cold work tool steels are employed to the manufacturing of tools for applications involving surface temperatures of not more than $200^{\circ} \mathrm{C}$. In this temperature range, they must feature the following properties in order to guarantee tool resistance to the high stresses arising from the numerous machining and shaping procedures [10] [11] [12]:

- superior hardness;

- high wear resistance;

- good toughness;

- excellent compressive and impact strength;

- high dimensional stability in heat treatment;

- sufficient machinability.

A well-balanced alloy content ensures that optimum properties are achieved for individual applications.

\subsection{Calculation of the Coefficient of Friction for the Strip Drawing Tests}

The friction force was acquired and the friction coefficient was calculated for

Table 1. Chemical composition, (average \%) [9] [10].

\begin{tabular}{|c|c|c|c|c|c|c|c|c|c|c|}
\hline Tool materials & & $\mathrm{C}$ & $\mathrm{Si}$ & $\mathrm{Mn}$ & $\mathbf{P}$ & $S$ & $\mathrm{Cr}$ & Mo & $\mathrm{V}$ & Other \\
\hline $\begin{array}{c}\text { K } 340 \\
(\mathrm{X} 110 \mathrm{CrMoV} 8-2) \mathrm{EN}\end{array}$ & & 1.10 & 0.90 & 0.40 & & 0.90 & 8.30 & 2.10 & 0.50 & $\begin{array}{l}+\mathrm{Nb} \\
+\mathrm{Al}\end{array}$ \\
\hline C 265 & Min & 1.45 & 0.10 & 0.20 & & & 11.0 & 0.70 & 0.70 & \\
\hline (X160CrMoV12-1) EN & $\operatorname{Max}$ & 1.60 & 0.60 & 0.60 & 0.030 & 0.030 & 13.0 & 1.00 & 1.00 & \\
\hline
\end{tabular}


constant speed and constant normal force. Each test was performed with lubricants. The corresponding plates involved four different surface conditions (grinded, polished, nitrided and quenched/tempered) and three different sliding speeds. Also, four different normal force values were applied. Therefore, twelve tests were performed for each tool plates set. But, for quenched/tempered tools only four tests have been completed because the surfaces of tools started to lose their quality from the begining of tests.

The tribosystem consists of the tool couples pressed at the required load $F_{N}$ against the test sheet in between, Figure 4.4. The operating parameters defined for the modified tribotester were as follows: normal load $F_{N} \approx 10.4,16.25,32.5$ and 48.75, $\mathrm{kN}$; sliding speed $v=60,150$ and 240, mm/min; steel sheet HSLA 380 Cold Rolled; tool contact area $A=40.5 \times 67.8=2746, \mathrm{~mm}^{2}$; lubricant Renoform EMP 172 (viscosity $68 \mathrm{~mm}^{2} / \mathrm{s}$ ).

During the tests, the friction force and the sliding distance were measured and a computer program was used to register and display the values of the friction force as a function of time or displacement.

The coefficient of friction is defined as the ratio of force of friction to the normal force, as seen in Equation (1). If the externally applied force $F_{N}$ is equal to the force of sliding friction $F_{p}$, then the object slides at the constant speed and the coefficient of friction involved is called the coefficient of sliding friction, $\mu$. The value of friction coefficient was determined based on the values of both normal force $F_{N}$ and pulling force $F_{p}$ from the formula (1). Equation (2) corresponds to the calculation of standard deviation for coefficient of friction. Equation (3) illustrate formula to obtain the apparent contact pressure $C_{p}$. The results of the experimental tests are presented in Table 2.

Table 2. Experimental results.

\begin{tabular}{cccccc}
\hline \multirow{2}{*}{ Surface condition } & Sliding speed, & \multicolumn{4}{c}{ Coefficient of friction } \\
\cline { 3 - 6 }$[\mathrm{mm} / \mathrm{min}]$ & $10.4 \mathrm{kN}$ & $16.25 \mathrm{kN}$ & $\mathbf{3 2 . 5} \mathrm{kN}$ & $\mathbf{4 8 . 7 5} \mathrm{kN}$ \\
\hline \multirow{2}{*}{ Grinded } & 60 & $0.143 \pm 0.002$ & $0.108 \pm 0.002$ & $0.099 \pm 0.001$ & $0.107 \pm 0.002$ \\
& 150 & $0.108 \pm 0.003$ & $0.122 \pm 0.001$ & $0.092 \pm 0.001$ & $0.097 \pm 0.002$ \\
& 240 & $0.104 \pm 0.002$ & $0.104 \pm 0.003$ & $0.088 \pm 0.002$ & $0.098 \pm 0.0006$ \\
\hline \multirow{2}{*}{ Polished } & 60 & $0.084 \pm 0.002$ & $0.081 \pm 0.0008$ & $0.069 \pm 0.001$ & $0.073 \pm 0.001$ \\
& 150 & $0.085 \pm 0.002$ & $0.082 \pm 0.002$ & $0.070 \pm 0.001$ & $0.079 \pm 0.0009$ \\
& 240 & $0.099 \pm 0.0004$ & $0.084 \pm 0.0006$ & $0.074 \pm 0.0008$ & $0.078 \pm 0.001$ \\
\hline \multirow{2}{*}{ Nitrided } & 60 & $0.136 \pm 0.009$ & $0.125 \pm 0.008$ & $0.107 \pm 0.004$ & $0.106 \pm 0.004$ \\
& 150 & $0.141 \pm 0.003$ & $0.138 \pm 0.003$ & $0.111 \pm 0.003$ & $0.118 \pm 0.001$ \\
& 240 & $0.164 \pm 0.003$ & $0.145 \pm 0.002$ & $0.124 \pm 0.004$ & $0.118 \pm 0.003$ \\
\hline \multirow{2}{*}{ Quenched/tempered } & 150 & $0.119 \pm 0.004$ & $0.216 \pm 0.014$ & $0.119 \pm 0.003$ & $0.182 \pm 0.04$ \\
& 240 & - & - & - & - \\
\hline
\end{tabular}




$$
\begin{gathered}
\mu=\frac{F_{p}}{2 F_{N}} \\
\sigma=\frac{F_{p \sigma}}{2 F_{N}} \\
C_{p}=\frac{F_{N}}{A}
\end{gathered}
$$

where, $\mu$-coefficient of friction; $F_{p}$-pulling force, $\mathrm{kN} ; F_{N}-$ normal force, $\mathrm{kN}$; $\sigma$-standard deviation; $F_{p \sigma}-$ pulling standard deviation; $C_{p}$-apparent contact pressure, $\mathrm{N} / \mathrm{mm}^{2} ; A$-area [7].

Data acquisition was started manually and stopped automatically when the pre set displacement was attained. The friction coefficient for the tests using constant speed was calculated by taking the mean value of the filtered friction function at $70 \%-90 \%$ of the travel distance. Experiments were repeated to check the distribution between deterministic experiments for different speed and applied forces.

The contact area between the tools and the sample is rectangular. Sheet has contact on both sides. The coefficient of friction between the tools and the surface of sheet metal is calculated according to Coulomb's friction law, as referred in Equation (4). The value of $F_{p}$, pulling force, is measured by a load cell attached to the modified machine, connecting the tested strip to the moving table. Following example presents calculation coefficient of friction for grinded surface tools under normal force $10.4 \mathrm{kN}$ and sliding speed $60 \mathrm{~mm} / \mathrm{min}$.

Similar tests were carried out using different loads and sliding speeds. The results for all tests are presented in Table 4.11.

$$
\mu=\frac{F_{p}}{2 F_{N}}=\frac{2.98}{20.8}=0.143
$$

where, $F_{p} \approx 2.98 \mathrm{kN} ; F_{N} \approx 10.4 \mathrm{kN} ; \mu \approx 0.143$.

\subsection{Discussion of Results}

This chapter deals with the measurement of friction with flat contacts. The demands on the testing equipment are severe, notably in regard to the flatness of the slider. An ideal experiment should give results which do not depend on the way of testing. This has been noticed by other researchers, but the nature of the effects is not always well known. In general, larger sliders give lower friction, but the precise influence of length and width of the slider may be different. A whole series of friction tests must be performed using one and the same slider [13] [14] [15]. But, on the other end, after the slider has been used once its surface has been modified and it is no more identical to its initial condition.

In the tests at different sliding speed, the influence of the mixed lubrication has been found. The higher pressure gave lower friction coefficient. To understand the phenomena in detail the exact conditions must be known and these cannot be derived from simple considerations. 
Another effect that has been encountered is that the friction at boundary condition may react strongly to minor changes in the surface texture. This indicates that friction experiments should be carried out in a comparative way, meaning that the tribological properties of a material can only be measured by comparing it with a 'standard' material in the same test. Furthermore, experiments should be carried in such a way that global changes in conditions do not influence the principal results. As a consequence, one should be careful to draw conclusions from the absolute value of the friction coefficient at mixed lubrication.

\section{Conclusions}

Friction measurements were conducted using a modified developed tribotester based on flat strip drawing. Four different tool surfaces were tested under similar contact conditions regarding contact area $\left(2746 \mathrm{~mm}^{2}\right)$, normal force, sliding speed, lubricant and surface characteristics to calculate the friction coefficient between the tool surfaces and steel sheet HSLA 380. The applied normal load was defined from 10 to $49 \mathrm{kN}$ and the sliding speed from $60 \mathrm{~mm} / \mathrm{min}$ to 240 $\mathrm{mm} / \mathrm{min}$.

Results of the experiments reveal that the modified strip drawing tribotester is a very useful tool to friction determination.

From test results, it was found that:

1) due to stability, generally $80 \%-90 \%$ of the sliding length was used for average friction determination; however, for quenched/tempered surfaces, only $25 \%-30 \%$ of the sliding length was possible to be used, due to more unstable sliding conditions;

2) the test method enables comparison of different tool surface finishes and lubricants in terms of friction under true sheet metal forming process conditions; valid frictional data is also very important as an input parameter for simulation models to achieve reliable results;

3) lubrication allows to minimize the effect of the directionality of tool surface topography on the friction behaviour by decreasing the range of friction coefficient value variation along the friction track length.

The ability to control the applied normal load and speed as a function of time creates great opportunities to improve tribotesting by reducing the number of tests.

\section{Conflicts of Interest}

The authors declare no conflicts of interest regarding the publication of this paper.

\section{References}

[1] Makhkamov, A. (2017) Tribology in Sheet Metal Forming. Ph.D. Thesis, Universidade do Porto, Porto.

https://scholar.google.ru/citations?view op=view citation\&hl=ru\&user=5U4KgJ4A

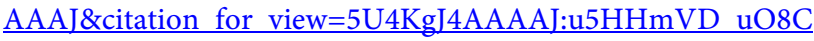


[2] Makhkamov, A., Wagre, D., Baptista, A.M., Santos, A.D. and Malheiro, L. (2017) Tribology Testing to Friction Determination in Sheet Metal Forming Processes. Ciência \& Tecnologia dos Materiais, 29, e249-e253.

http://www.scopus.com/inward/record.url?eid=2-s2.0-85022101135\&partnerID=M N8TOARS

https://doi.org/10.1016/j.ctmat.2016.07.002

[3] Kirkhorn, L., Bushlya, V., Andersson, M. and Stahl, J.E. (2013) The Influence of Tool Steel Microstructure on Friction in Sheet Metal Forming. Wear, 302, 1268-1278. https://doi.org/10.1016/j.wear.2013.01.050

[4] Trzepieciński, T., Bazan, A. and Lemu, H.G. (2015) Frictional Characteristics of Steel Sheets Used in Automotive Industry. International Journal of Automotive Technolo$g y, 16,849-863$. https://doi.org/10.1007/s12239-015-0087-1

[5] Makhkamov, A., Wagre, D., Baptista, A.M. and Santos, A.D. (2015) Friction Determination and Tribology Testing in Sheet Metal Forming. Doctoral Congress in Engineering-DCE 2015, Porto, 11-13 June 2015, 135 p. https://scholar.google.ru/citations?view op=view citation\&hl=ru\&user=5U4KgJ4A AAAJ\&citation for view=5U4KgJ4AAAAJ:dhFuZR0502QC

[6] Makhkamov, A., Amaral, R., Baptista, A.M., Santos, A.D. and Malheiro, L. (2017) Determination of the Friction Coefficient in the Flat Strip Drawing Test. Doctoral Congress in Engineering-DCE 2017, Porto, 8-9 June 2017, 145 p.

https://scholar.google.ru/citations?view op=view citation\&hl=ru\&user=5U4KgJ4A AAAJ\&citation for view $=5 \mathrm{U} 4 \mathrm{Kg}$ J4AAAAJ:L8Ckcad2t8MC

[7] Blau, P.J. (2009) Introductory Mechanics Approaches to Solid Friction. In Friction Science and Technology, CRC Press, Boca Raton, 17-41.

[8] Makhkamov, A., Abduvkhidov, M., Akramjonov, D. and Rakhimberdiyev, D. (2019) Investigation of the Issues of Analytical Determination of the Stiffness Parameters of Batch Structures. Universum: Technical Science, 4, 16-20.

https://scholar.google.ru/citations?view op=view citation\&hl=ru\&user=5U4KgJ4A AAAJ\&citation for view=5U4KgJ4AAAAJ:9yKSN-GCB0IC

[9] Makhkamov, A., Abduvkhidov, M., Siddiqov, A. and Kholmirzayev, F. (2018) Investigation of the Analytical Determination of the Stiffness Parameters of Batch Structures. International Conference of Science and Practice: A New Level of Integration in the Modern World, Berlin, 27 April 2018, 143-146.

[10] Takadoum, J. (2007) Materials and Surface Engineering in Tribology. ISTE Ltd., London. https://doi.org/10.1002/9780470611524

[11] Ramada. Aços Para Ferramentas de Trabalho a Frio. http://www.ramada.pt/pt/-produtos/acos/aa-os-para-ferramentas-de-trabalho-a-fri o/c-265 html

[12] Markenübersicht Kaltarbeitsstähle Survey of Cold Work Tool Steel Grades. http://docplayer.org/43647662-Markenuebersicht-kaltarbeitsstaehle-surveyofcoldw ork-tool-steel-grades.html

[13] Makhkamov, A., Khusanov, S., Muradov, R. and Karimov, A. (2020) Mathematical Modeling of Separation of Raw Cotton from the Air Flow under the Action of Centrifugal Force. Universum: Technical Science, 5, 15-20.

[14] Makhkamov, A., Khusanov, S., Muradov, R. and Imomaliyeva, S. (2020) The Oretic Observation of the Cotton Movement in the Operating Camera of the New Separator. International Journal of Psychosocial Rehabilitation, 24, 6356-6364.

[15] Makhkamov, A., Khusanov, S., Muradov, R. and Karimov, A. (2020) Study of the Effect of the Mobile Floor of the Separator Device on the Cotton Section. International Journal of Psychosocial Rehabilitation, 24, 6473-6481. 